\title{
Elektrikli ve Elektronik Eşya Atıklarının Geri Dönüşümü Konusunda Halkın Bilinç Düzeyinin Ölçülmesi: Sivas İli Örneği
}

DOI: $10.26466 /$ opus.548371

*

\section{İlknur Sentürk*}

* Dr. Öğr. Üyesi, Sivas Cumhuriyet Üniversitesi, Mühendislik Fakültesi, Sivas / Türkiye E-Posta: ilknurg.senturk@gmail.com

ORCID: $\underline{0000-0002-8217-2281}$

\section{Öz}

Son yıllardaki teknolojik ilerlemenin kaçınılmaz sonucu olarak, dünyada elektrikli ve elektronik eşya tüketimindeki artış, atık elektrikli ve elektronik eşya (AEEE) problemini de beraberinde getirmiştir. Bu atıklar yapısında toksik madde barındırdığı ve büyük alanları işgal ettiği için, AEEE problemi bizim düşündü̈̆̈̈müzden çok daha büyüktür. Günümüzde să̆llklı koşullar altında e-atıklar içindeki ağır metalleri geri kazanmak ve geri dönüşümünü sağlamak çevre ve insan sağhlğ̆ için oldukça önemlidir. Bu noktada hem üreticiler hem de tüketicilerin daha duyarlı davranması ve konu hakkında bilgilendirilmesi gerekir. Bu çalışma, Sivas il merkezinde yaşayan halkın elektrikli ve elektronik atıklarından kurtulma yöntemi konusundaki tüketici davranışları, e-atıklar konusundaki bilinç düzeyi ve tutumlarının belirlenmesi için yapılmıştır. Sivas merkezde ikamet eden 100 kişi basit rastgele örnekleme yöntemine göre seçilmiş ve bireylere yüz yüze anket tekniği uygulanmıştır. Ankete katılan bireylerin \%23'ü ile sokakta, \%42'si ile evde, \%35'i ile işyerlerinde görüşülmüştür. Katılımciların çoğu AEEE yani e-atık tehlikesinin farkındadır ancak bu atıklardan kurtulmak için uygun yöntemin ne olduğunu bilmemektedir. Bu nedenle tüketicilerin, e-atıklarını ne yapmaları konusunda bilgilendirilmesi ve e-atıkların yönetmeliğe uygun olarak atmalar konusunda motive edilmeleri gerekmektedir. Коnu hakkında tüketiciler bilgilendirildiğgi takdirde halkın elektrikli ve elektronik eşya atıklarının geri dönüşümü konusunda destek olacakları anlaşılmaktadır.

Anahtar Kelimeler: Anket, AEEE, E-atık yönetimi, Sivas, Tüketici davranışı 


\title{
Measurement of Awareness Level of Public in the Recycling of Electrical and Electronic Wastes: A Case of Sivas City
}

\begin{abstract}
As an inevitable consequence of technological progress in recent years, the increase in the consumption of electrical and electronic equipment in the world has brought the problem of waste electrical and electronic equipment (WEEE). The problem of WEEE is much bigger than we thought because these wastes contain toxic substances and occupy large areas. Today, recovering and recycling of heavy metals in e-wastes under healthy conditions is very important for the environment and human health. At this point, both producers and consumers need to be more sensitive and informed about the issue. This study was carried out to determine awareness level and attitudes about e-wastes, consumer behaviors on the way of getting rid of electrical and electronic waste of consumers living in the city center of Sivas, Turkey. 100 people living in the center of Sivas were selected according to the simple random sampling method and the face-to-face survey technique was applied to the individuals. Survey work was made in the street with $23 \%$, in the home with $42 \%$, and in the workplaces with $35 \%$ of individuals. Most of the participants are aware of the WEEE about e-waste hazard, but they do not know what is the proper way to get rid of these wastes. For this reason, consumers need to be motivated and informed about the disposal and management of their e-waste. If consumers are informed about the matter, it is understood that the public will support the recycling of electrical and electronic waste.
\end{abstract}

Keywords: Survey, WEEE, E-waste management, Sivas, consumer behavior 


\section{Giriş}

Dünya, bilgi toplumu olma yolunda hızlı adımlarla ilerlerken, elektronik cihazların kullanım ömürleri her geçen gün azalmaktadır. Kendisini sürekli olarak daha hızlı, daha verimli, daha şık, daha ekonomik şeklinde pazarlayan günümüz eğilimleri sayesinde, sahip olduğumuz elektronik cihazlar çok değil 1 ila 6 yıl içerisinde "iş görmez" veya "tamiri yenisini almaktan daha pahalı" hale geldiği için yüksek fiyatlarla çok beğenerek almış olduğumuz elektronik eşyalar en sonunda hurdacılara ya da çöpe gitmektedir. Sahibi tarafından elden çıkarılan bu ürünler "e-atık" adı verilen atık türünü ortaya çıkarmış olmaktadır (Çiftlik ve diğ., 2011). Eatık (elektronik atık) ya da AEEE (Atık Elektrikli ve Elektronik Eşya), kullanım ömrünü tamamlamış olan, içerisinde bir veya daha fazla elektrik iletim elemanı bulunduran ürünlere verilen addır (İnce, 2011). Elektrikli ve elektronik atıklar çoğunlukla evlerde kullanılan büyük elektronik ekipmanlardan (örneğin televizyonlar, kişisel bilgisayarlar, buzdolapları, cep telefonları, DVD/VHD makineleri ve elektrik tasarruflu ampuller vb.) oluşur. Bu atıklardan değerli olan kısımların geri kazanılması ülke ekonomisine katkı sunacağı gibi, uzaklaştırılması gereken tehlikeli bileşikler de atık yönetimi çerçevesinde işlenmiş olacaktır.

Elektrikli ve elektronik eşya atıklarının artış oranları, kentsel atıklardan 3 kat daha büyük olmasına karşın günümüzde halen elektrikli ve elektronik ekipman atıklarının toplama, işleme, yenileme oranları oldukça düşüktür (Burke 2007; Ay 2012). Oysaki kullanım ömrünü tamamlayan elektronik cihaz ve ekipmanlar içerisinde bulunan değerli maddeler (Tablo 1), yeniden kullanım ve geri kazanıma uygunluğu dolayısıyla oldukça önemli bir ikincil hammadde kaynağıdır. Fakat eatıklar uygun bir şekilde ayrıştırılıp bertaraf edilmediğinde önemli birer toksik madde kaynağına dönüşerek içerdikleri tehlikeli bileşenler nedeniyle insan ve çevre sağlığı açısından büyük sorunlara yol açacaktır. Balde et al., (2014) 52 milyar \$'lık bir kaynak anlamına gelen bu e-atığın sadece küçük bir kısmının (\%16'dan daha düşük bir miktarı) uygun bir şekilde geri kazanımının yapıldığını rapor etmiştir. 
Tablo 1. Atık elektrikli ve elektronik eşyalar içerisinde kullanılan başlıca kıymetli metaller (Neira ve diğ., 2006)

\begin{tabular}{ll}
\hline Kıymetli metaller & \multicolumn{1}{c}{ Kullanım alanları } \\
\hline Altın & Elektronik: Bilgisayarlar, cep telefonları \\
& Elektronik: Bilgisayarlar, cep telefonları, fotovoltaik ve \\
& katalizörler \\
Platinyum & Otomotiv katalizör \\
Paladyum & Otomotiv katalizör \\
Rodyum & Düz paneller, elektrik sektörü \\
Rutenyum & Elektronikler: Bilgisayar, hard-disk \\
Bakır & Elektrikli ve elektronik cihazlar: Bilgisayarlar, cep telefonları \\
Kobalt & Katalizörler, bataryalar \\
\hline
\end{tabular}

Çin'in Guiyu bölgesindeki e-atık geri dönüşüm alanına yakın Nanyang Nehri'nde yapilan analizlerde, polibromlu difenileter (PBDE) konsantrasyonu nehir suyunda $760 \mathrm{ng} / \mathrm{g}$, sediment örneklerinde 16.000 ng/g seviyelerinde ölçülmüştür (Luo et al., 2007). Robinson (2009) sağlıksız metotlarla e-atık geri dönüşümü yapılan yerlerin yakınındaki nehir suyunda kurşun $(\mathrm{Pb})$ seviyesinin, normal bir nehirdeki $\mathrm{Pb}$ seviyesinden 4 kat daha fazla olduğunu belirtmiştir. Ha et al., (2009) e-atık geri dönüşümü yapan bir tesis yakınlarından aldıkları hava örneklerindeki $\mathrm{Pb}$, bakır $(\mathrm{Cu})$ ve çinko $(\mathrm{Zn})$ seviyesinin e-atık geri dönüşümü olmayan bölgeye göre 5 kat yüksek olduğunu rapor etmiştir (Salihoğlu ve Kahraman, 2016).

E- atıklar çoğunluğu zehirli olan 1000'den fazla madde içerdiğinden uygun ayrıştırma işlemlerinden geçmeden direk deponi alanlarına gönderildiklerinde önemli çevre kirliliklerine sebep olması kaçınılmazdır. Örnek verilirse bir TV Katot ışın (CRT) 2-4 kg kurşun, büyük TV ekranı ise ondan daha da fazla kurşun içermektedir. Toprak dolgusundaki ağır metallerin örneğin $\mathrm{Pb}, \mathrm{Cd}$ ve $\mathrm{Hg}^{\prime}$ nin \%40' dan fazlası e-atıklardan kaynaklanmaktadır. Ağır metaller besin zinciri yoluyla canlı yapısına girerek birikmekte ve insan sağlı̆ı üzerinde ölümcül etkilere sebep olabilmektedir (Aydın ve Kiraz, 2017). Örneğin Güney Çin'de (e-atık geri dönüşüm bölgelerinden biri) inhalasyon yoluyla ağır metallere maruz kalan kişilerin sağlık durumunu değerlendirmek amacıyla 2012'de yapılan taramada bu kişilerin ömür boyu kansere yakalanma riski anlamlı olarak yüksek bulunmuştur (Huanga ve diğ., 2016). E-atık geri 


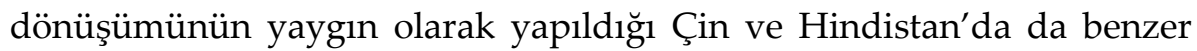
çalışmalar yapılmış, bu tarz atıklara maruz kalan kişilerin vücutlarında bu metallere rastlanmıştır.

Elektrikli ve elektronik ekipmanlar plastik, polivinil klorür (PVC), polietilen (PE), polyester (PET ve PBT vb.), cam, ahşap, metal gibi farklı birçok materyal içerdiğinden oldukça kompleks yapıdadır. Dolayısıyla geri kazanım işlemleri de oldukça karmaşıktır (Kang ve Schoenung, 2005). Elektrikli ve elektronik atıkları tehlikeli atık gurubu haline getiren içermiş oldukları cıva, kurşun, kadmiyum ve krom (+6), baryum, berilyum gibi ağır metaller, kloroflorokarbon (CFC), poliklorlu bifeniller (PCB), PVC ve bromlu alev geciktiriciler (BAG) gibi halojenli bileşikler, fosfor ile asbest ve arseniktir (Tablo 2). Hepimiz bu tarz tehlikeli atık içeren cep telefonu, bilgisayar, TV/radyo, ampul, floresan gibi eşyaları kullanmaktayı. Bu nedenle birçok e-atığ 1 hayatımızın bir döneminde hiç değilse 1 kez atmış ya da atılmak üzere gözden çıkarmışızdır. En çok da enerji tasarruflu ampuller atılmaktadır. Bu ampuller, cıva gibi tehlikeli kimyasalların çoğunu yapısında barındırır. Bu nedenle, çevrenin korunması için bu tür atıkların, kontrollü bir şekilde bertarafı oldukça önemlidir (US EPA, 2001).

Diğer bir kirletici grubu ise bromlu alev geciktiricilerdir (BAG). Daha ekonomik olması, daha kolay işlenebilmesi ve üretilen ürünlerin daha hafif olması nedeniyle, elektronik sektörünün ana maddeleri haline gelen plastik ya da petrol türevi malzemelerin yanmasını geciktirmek amacı ile kullanılan BAG; bromlu bifenoller, bifeniller, fenoller gibi farklı özellikteki çok sayıda kimyasal maddeyi kapsamaktadır. BAG, baskı devre elemanları, bağlantı elemanları, kablolar ile televizyon ve mutfak eşyaları gibi elektronik ürünler olmak üzere günümüzde hemen hemen tüm elektronik ürünlerde alev almaya/yanmaya karşı koruyucu olarak kullanilmaktadır (US EPA, 2001; Sjodin, 2003). Fakat koruyucu olarak kullanılan bu madde yakıldığında dioksin olarak ortaya çıkmakta ve atmosfere yayılmaktadır. Atıkların yakılarak bertaraf edilmesinin neden olduğu kurşun emisyonlarının önemli bir kısmının elektronik atıklardan kaynaklandığ tespit edilmiştir. 
Tablo 2. Atık elektrikli ve elektronik ekipman içinde bulunan başlıca tehlikeli bileşenler (He ve diğ., 2006)

\begin{tabular}{ll}
\hline Materyal ve bileşenler & Tanımı \\
\hline Akü, pil, batarya & $\begin{array}{l}\text { Kurşun, cıva ve kadmiyum gibi ağır metaller bu } \\
\text { bileşenler içinde bulunur. }\end{array}$ \\
\hline $\begin{array}{l}\text { Monitör ve televizyonlarda } \\
\text { kullanılan katot ışın tüpleri } \\
\text { (CRT) }\end{array}$ & $\begin{array}{l}\text { Cam panelin iç kısmındaki floresan kaplamada } \\
\text { kullanılır ve yüksek oranlarda kurşun, baryum, } \\
\text { fosfor gibi ağır metaller içerir. }\end{array}$ \\
\hline Cıva içeren bileşenler & $\begin{array}{l}\text { Cıva; termostat, sensör, röle ve anahtarlar (switch) } \\
\text { içinde kullanılır. Ayrıca medikal ekipmanlar, veri } \\
\text { transferi, telekomünikasyon ve cep telefonlarında } \\
\text { kullanılır. }\end{array}$ \\
\hline Asbest atığ1 & - \\
\hline Toner kartuşu & - \\
\hline $\begin{array}{l}\text { Bilgisayarlardaki } \\
\text { devre kartı baskı }\end{array}$ & Bazı bileşenlerinde kadmiyum içerir. \\
\hline Poliklorlu bifeniller & - \\
\hline Kondansatörler & - \\
\hline Sıvı kristal ekranlar & - \\
\hline Bromlu alev geciktiriciler & $\begin{array}{l}\text { Elektronik cihazlardaki plastiklerin yanmasını } \\
\text { engellemek için kullanılır. }\end{array}$ \\
\hline Alev almayı geciktiriciler & $\begin{array}{l}\text { Halojenli alev geciktiriciler, yakıldıkları takdirde } \\
\text { dioksin olarak ortaya çkmakta ve atmosfere } \\
\text { yayılmaktadır. }\end{array}$ \\
\hline $\begin{array}{l}\text { Hidrokloroflorakarbon ya } \\
\text { da hidroflorakarbon içeren } \\
\text { ekipmanlar }\end{array}$ & \begin{tabular}{l} 
Bu maddeler soğutucu ve köpükler içinde bulunur. \\
\hline Gaz deşarjlı lambalar
\end{tabular} \\
\hline
\end{tabular}

Yukarıda da anlatıldığı üzere elektrikli ve elektronik cihazlar hem kimyasal hem de fiziksel olarak belediye ya da sanayi atıklarından farklı özelliklere sahiptir. Bu özelliklerinden ötürü cihazlar kullanım ömürlerini tamamladıklarında, uygun bir biçimde geri kazanılması ya da bertaraf edilmesi gerekir. Kontrolsüz bir şekilde atılan elektrikli ve elektronik atıklar enfeksiyon yapıcı hastalıkların yayılmasına, toksik maddelerin gıda zincirine geçmesine ve içme suyu kalitesinin bozulmasına yol açmaktadır. Elektronik aygitlar içinde bulunan kimyasalların çoğu çevresel açıdan dirençli oldukları için, doğada uzun yıllar boyunca 
kalarak çevre ve insan sağlığını olumsuz yönde etkilemesi kaçınılmazdır (Mburu ve Tuduetso, 2013; Robinson, 2009).

$\mathrm{Bu}$ atıklar doğru tekniklerle ayrıştırıldığında çevre veya sağlık için hiç bir soruna yol açmamaktadır. Ancak gerekli güvenlik önlemlerini almadan yapılan işlemler, birinci derecede atığı işleyen kişilere zarar vermekte, işleme ortamındaki toprağa sızmakta, sızıntılar yeraltı suyuna ulaşarak içme suyu kaynaklarını kirletme riski taşımaktadır. Katı atık depolama alanlarında bulunan kurşunun ortalama olarak \%40'ının, elektronik atıklardan kaynaklandığı tahmin edilmektedir. Depolama alanlarında yeterli önlem alınmaması durumunda atık içindeki krom sızarak kolaylıkla su kaynaklarına ulaşabilir. Cıvalı bileşenler de uzun dönemde aynı etkiyi gösterecektir (Akin ve Kuru, 2011).

\section{Türkiye'de AEEE Yönetimi}

Uluslararası bir girişim olan Solving the E-waste Problem (StEP) tarafından sunulan sonuçlara göre, 2013 yılında dünyada 48,9 milyon ton e-atık üretilmiştir. StEP, bu rakamın \%33 artarak 2017'de 65,4 milyon tona ulaşacağını öngörmektedir (Özkan, 2018). Dünyada en fazla elektronik atık üreten ülkeler; 1 . sırada ABD 7 milyon ton, 2. sirada Çin 6 milyon ton ve 3. sirada Japonya 2,2 milyon tondur (Kaya \& Koruca, 2018). Türkiye'deki atık üretimi ise 503 bin ton olup (kişi başına düşen e-atık miktarı da 6,5 kilogram) diğer ülkeler arasında 17'nci sırada yer almaktadır (Gündüzalp \& Güven, 2016; Aydın \& Kiraz, 2017). Avrupa birliğinin 2014 yılında düzenlediği rapora göre Türkiye'nin 2024 yılına kadar olan e-atık miktarının \%12 artacağı tahmin edilmektedir. Üretilen atık miktarına rağmen Türkiye'de geri dönüşüm oranı yaklaşık \% 5 tir (Kaya ve Koruca, 2018).

Gelişmekte olan ülkeler kategorisindeki ülkemizde elektronik atık bertarafı bilgisayar (monitör, kasa, klavye, mouse, vs), yazıcı, tarayıcı, faks, fotokopi makinesi, telefon, cep telefonu, televizyon, müzik aletleri, küçük ev aletleri, kartuş, toner, kablo, switch, röle, konnektör gibi elektronik bileşenler ve diğer elektrikli ve elektronik tüm malzemeleri kapsamaktadır. Bu atıklar içerisinde bulunan plastiklerin çok büyük bir kısmı geri dönüştürülemezken en çok metal aksamların geri dönüşümü sağlanmaktadır. Geri kazanılan metallerin büyük bir kısmı ise 
otomotivden beyaz eşyaya kadar bu metalleri hammadde olarak kullanan firmalara gönderilmektetir. Elektronik devreler ögütülmek üzere yurt dışına gönderilirken, monitör camı gibi sadece kendi yapımında hammadde olarak kullanılabilen materyaller tekrardan elektronik firmalarına iletilmektedir (Çelik, 2007). Çevre ve Şehircilik Bakanlığ (2017) verilerine göre Türkiye' de 69 tane lisanslı e-atık işleme tesisi vardır. Tesislerin çoğunluğu nüfus ve sanayileşme gibi faktörlerin de etkisiyle Ankara, İstanbul, Kocaeli, Bursa ve Eskişehir gibi illerde yoğunlaşmıştır. $\mathrm{Bu}$ tesislerde toplanan atıklar ekonomiye tekrardan kazandırılmaktadır.

E-atık geri dönüşüm işleminden metal eldesi sırasında harcanan enerji, cevherden metal eldesi sırasında kullanılan enerji miktarından düşük olduğu için önemli bir enerji tasarrufu da sağlanmış olur (Yazıcı \& Deveci, 2009). Örneğin, geri kazanılmış metalden 1 ton alüminyum yapmak için gereken enerji, boksitten yapılacak alüminyum için harcanan enerjinin \%4'ü, aynı şekilde bakır bileşimlerinin geri kazanılması için gereken enerji, bu metalin doğal kaynaklardan çıkartılması için gereken enerjinin sadece \%13'ü ve demir-çelik için \%19'u kadardır (Karagözoğlu ve diğ, 2009). Birçok bilim adamı da en kötü geri dönüşüm faaliyetinin, en verimli madencilik çalışmasından daha iyi sonuç verdiğini söylemektedir. Örneğin bir ton bilgisayar atığındaki altın miktarının, yaklaşık 15 ton altın cevherinden elde edilecek olandan daha fazla olduğu tespit edilmiştir (Aydın ve Kiraz, 2017). Dünya genelinde plastik, alüminyum, bakır, altın ve çelik gibi maddelere olan ihtiyaç her geçen gün arttığından, bu gereksinimi sadece madencilik faaliyetlerinden sağlamak hem finansal açıdan hem de çevresel açıdan mümkün gözükmemektedir (Çiftlik ve diğ., 2011).

\section{Araştırmanın Amacı}

Sivas'ta oluşan e-atık adedi ve büyüklüğü tam olarak bilinmemektedir. Ayrıca elektrik elektronik atıklarını atma konusunda tüketici davranışlarını analiz eden bir araştırmaya da rastlanmamıştır. E-atık atılması yönündeki tüketici davranışları çevresel risklerin artmasında oldukça etkili olduğu için böyle bir araştırmaya gerek duyulmuştur. Araştırmanın amacı, Sivas il merkezinde yaşayan bölge halkının elektrikli ve elektronik atıkların geri kazanımı konusundaki tutum, davranış, bilgi 
düzeyi ve alışkanlıklarını tespit etmektir. Araştırma sonuçları, AEEE’lerin geri kazanımı ve toplanması amacıyla yapılan faaliyetlerin daha verimli bir şekilde gerçekleştirilmesinde, uygulamadaki aksaklıkların giderilmesinde ve bu tarz atıkların geri kazanımı yönünde uygulanacak politika ve eğitimlerin planlanmasında yol gösterici olacaktır.

\section{Materyal ve Metot}

Sivas il merkezinde yaşayan gelir düzeyi, yaşı, mesleği farklı 100 kişi ile yüz yüze görüşülerek anket çalışması yapılmıştır. Ankete katılan bireylerin \%23'ü ile sokakta, \%42'si ile evde, \%35'i ile işyerlerinde görüşülmüş ve önceden hazırlanmış olan 12 farklı soru yöneltilmiştir. Ana kütleden seçilen örnekteki kişiler basit rastgele örnekleme yöntemine göre seçilmiş ve ankete katılanların demografik özellikleri Tablo 3'de verilmiştir.

Tablo 3. Ankete katılanların demografik özellikleri

\begin{tabular}{cccc}
\hline \multicolumn{3}{c}{ Yaş aralığı } \\
\hline & $<20$ yaş & $20-40$ yaş & $>40$ yaş \\
& $\% 14$ & E66 & \\
\hline & \multicolumn{3}{c}{ Eğitim durumu } \\
\hline İlköğretim & Lise & Önlisans & Lisans \\
$\% 23$ & $\% 34$ & $\% 10$ & $\% 33$ \\
\hline \multicolumn{4}{c}{ Meslek } \\
\hline Öğrenci & Ev Hanımı & Emekli & Çalışan (Esnaf, İşçi, Memur) \\
$\% 29$ & $\% 4$ & $\% 6$ & $\% 61$ \\
\hline \multicolumn{4}{c}{ Gelir durumu (TL) } \\
\hline $1000-4000$ & $4000-6000$ & $6000-8000$ & $>8000$ \\
$\% 77$ & $\% 15$ & $\% 7$ & $\% 5$ \\
\hline
\end{tabular}

\section{Bulgular ve Tartışma}

Bu bölümde, yöneltilen anket sorularına katılımcıların verdiği cevaplar değerlendirilmiştir. İlk 6 soru ve bu sorulara verilen cevaplar Tablo 4'de yer almaktadır.

AEEE'lerin kontrolü yönetmeliği 2012 yılından beri Ülkemizde uygulanmaktadır. Buna rağmen katılımcıların yönetmelik hakkında 
yeterli bilgiye sahip olmadığı 1 . soruya verilen cevaplardan anlaşılmaktadır.

Tablo 4. Ankete katılanlara yöneltilen sorular

\begin{tabular}{|c|c|c|c|c|}
\hline & \multirow[b]{2}{*}{ Soru } & \multicolumn{3}{|c|}{ Katılımcıların Cevapları (\%) } \\
\hline & & Evet & Hayır & $\begin{array}{l}\text { Fikrim yok (F) } \\
\text { Bilmiyorum (B) } \\
\text { Ilgilenmiyorum } \\
\text { (I) }\end{array}$ \\
\hline 1 & $\begin{array}{l}\text { Türkiye' de elektrikli ve elektronik } \\
\text { ekipman atıklarının yönetimi ile } \\
\text { ilgili yasa, tüzük, yönetmelik vb. } \\
\text { olup olmadığı hakkında bilgi sahibi } \\
\text { misiniz? }\end{array}$ & 41 & 32 & $27(\mathrm{~F})$ \\
\hline 2 & $\begin{array}{l}\text { Buzdolabı, derin dondurucu, klima } \\
\text { gibi elektronik cihazların } \\
\text { yapısındaki kloroflorokarbon (CFC) } \\
\text { gazlarının insan sağlığı üzerinde } \\
\text { olumsuz etkileri olup olmadığı } \\
\text { hakkında bilgi sahibi misiniz? }\end{array}$ & 58 & 42 & - \\
\hline 3 & $\begin{array}{l}\text { Kullandığınız elektrikli ve } \\
\text { elektronik ürünlerin çöpe } \\
\text { atılmamasını belirten herhangi bir } \\
\text { uyarı yada sembol dikkatinizi çekti } \\
\text { mi? }\end{array}$ & 52 & 39 & $9(\mathrm{~B})$ \\
\hline 4 & $\begin{array}{l}\text { Ülkemizde veya çevrenizde } \\
\text { elektrikli ve elektronik ürünler veya } \\
\text { parçaları için özel olarak } \\
\text { yerleştirilmiş atık kutularına } \\
\text { rastladınız mı? }\end{array}$ & 30 & 70 & - \\
\hline 5 & $\begin{array}{l}\text { Yaşadığınız çevrede bu tarz geri } \\
\text { dönüşüm kutuları olsa, e- } \\
\text { atıklarınızı bu kutulara atar } \\
\text { mısınız? }\end{array}$ & 74 & 21 & $5(\mathrm{~B})$ \\
\hline 6 & $\begin{array}{l}\text { Atık elektrikli ve elektronik } \\
\text { eşyaların geri kazanımı konusunda } \\
\text { Belediyelerin görev, yetki ve } \\
\text { sorumlulukları hakkında bilginiz } \\
\text { var mı? }\end{array}$ & 58 & 38 & $4(\dot{\mathrm{I}})$ \\
\hline
\end{tabular}


2. soruya katılımcıların \%58'i evet, \%42'si ise hayır demiştir. Katılımcıların \%66'sı 20-40 yaş aralığında olmasına rağmen çevre konusunda yeterli bilgiye sahip olmadıkları anlaşılmaktadır. Klima sistemleri ve buzdolaplarında kullanılan kloroflorokarbon gazları sera etkisine bağlı iklim değişikliği ve ozon tabakasının incelmesine neden olmaktadır. Bu nedenle CFC içeren EEE atıklarının kontrollü bir şekilde ayrıştırılabilmesi için atık sahiplerinin bilgilendirilmesi, bu tarz atık eşyalarını nereye verecekleri konusunda yönlendirilmesi önemli bir gereklilik olarak ortaya çıkmaktadır.

Ankete katılanların 3. soruya verdiği cevaplar Tablo 4'de verilmiştir. AEEE Kontrolü Yönetmeliği'ne göre, yönetmeliğin yürürlüğe giriş tarihinden sonra Elektrikli ve Elektronik Eşya Üreticileri; piyasaya sürülen EEE'leri Şekil 1'de yer alan sembolle işaretlemekle yükümlüdür. Elektrikli ve Elektronik Eşya Dağıtıcıları ise; satış yerlerinde tüketicilerin kolaylıkla görebileceği yerlerde evsel AEEE'lerin toplanması, geri dönüşümü, diğer evsel AEEE toplama noktaları, Şekil 1'de yer alan sembol ve bu sembolün anlamına ilişkin bilgileri bulundurmakla yükümlüdür (Resmi Gazete, 2012). Verilen cevaplardan kişilerin yönetmeliğin uygulamaya konduğu tarihten sonra EEE'lerini değiştirmedikleri ya da elektrikli ve elektronik eşya dağıtıcılarının bu konuda yeterli bilgilendirme yapmadıkları anlaşılmaktadır.

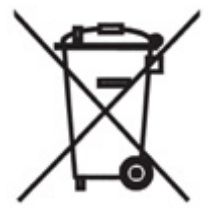

\section{Şekil 1. AEEE işareti}

4. soruya katılımcların \%30'u evet cevabını verirken, \%70'i hayır demiştir. Yüz yüze görüşmede daha önce büyük şehirlerde yaşamış ve yurt dışında çalışıp tekrar memleketine dönen kişiler böyle bir kutuya rastladığını belirtmiştir. Ancak bu durumda olmayan katılımcılar, bu tarz geri dönüşüm kutularını görmediğini belirtmiştir. Bu oran, Sivas ilinde AEEE toplanması konusunda yeterli çalışmanın yapılmadığının da göstergesidir. 
5. soruya verilen cevaplardan, İlde toplama merkezleri kurulmasi halinde insanların büyük çoğunluğunun elektronik atıklarını bu kutulara atacakları anlaşılmaktadır. E-atık ürünü bulunan kişilerin rahatlıkla ulaşabileceği şekilde e-atık çöp konteynırlarının yerleştirilmesi bu atıkların toplanmasında oldukça önemlidir. Böylece çevre ve insan sağlığ önemli oranda korunurken, bu atıklardan ekonomik kazanç elde edebilmek için gerekli ilk aşama olan toplama işlemi de sağlanmış olacaktır.

6. soruda katılımcıların \%58'i bu konuda bilgisi olduğunu, \%38'i hiçbir bilgisi olmadığını \%4'ü ise konu ile ilgilenmediklerini ifade etmiştir. 2012 yılında yürürlüğe giren AEEE'lerin Kontrolü Yönetmeliği Madde 8'de Belediyelerin görev ve sorumlulukları tanımlanmıştır. Buna göre Belediyeler, AEEE'lerin diğer atıklardan ayrı toplanmasını sağlamak için yönetim planı oluşturulması, toplama programı hakkında konutların bilgilendirilmesi ve programa uyulmasi, getirme merkezlerini kurarak AEEE'lerin toplanmasının sağlanması ve kurulan getirme merkezleri hakkında halkın bilgilendirilmesi ve toplanan AEEE'lerin lisanslı işleme merkezlerine gönderilmesi ile yükümlüdür (Resmi Gazete, 2012). Ancak diğer sorulara da verilen yanitlardan Belediyenin, bu konudaki yükümlülüklerini henüz tam olarak yerine getiremediği anlaşılmaktadır.

\section{Soru 7. Eskimiş, bozulmuş ve kullanmadığınız elektrikli ve elektronik eşyalarınızı nasıl değerlendiriyorsunuz?}

Bu soru ile e-atık yönetiminde en önemli zincir konumundaki tüketicilerin e-atık değerlendirme eğilimlerinin tespit edilmesi amaçlanmıştır. Katılımcıların vermiş olduğu cevaplar Şekil 2'de verilmiştir. "Hurdacıya satıyorum" \%46 ile en fazla işaretlenen cevap olmuştur. Diğer cevaplardan çıkan sonuç da göstermiştir ki, halkın elektronik atıklardan bir ekonomik değer beklentisi bulunmaktadır.

$\mathrm{Bu}$ atıkların uygun şekilde yönetilebilmesi için dünyanın değişik ülkerinde yönetmelikler yayınlanmaktadır. Fakat yasa dışı olarak AEEE toplayan hurdacılar her yerde vardır. O yüzden devlet desteği ile bu hurdacıların atık geri kazanım sistemine dahil edilmeleri oldukça önemlidir. Sivas İli elektronik atık yönetim stratejisinin belirlenmesinde, 
katılımcıların verdiği cevaplar ve hurdacıların sistem içindeki payı dikkate alınmalıdır.
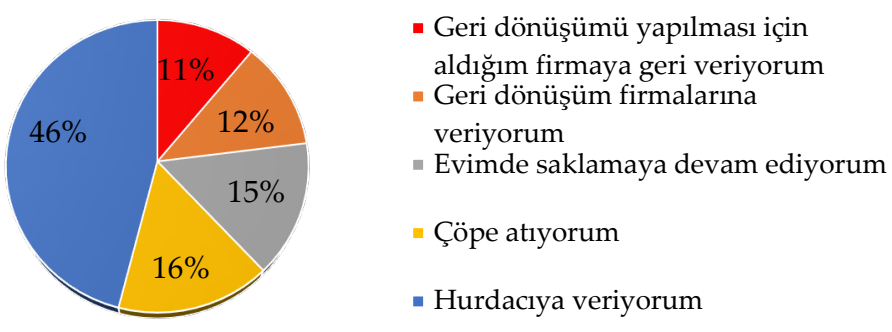

Şekil 2. Elektrikli ve elektronik eşyaların değerlendirilme şekli

Birebir görüşmede katılımcılar AEEE'lerini nasıl değerlendirmeleri gerektiği konusunda yeterli bilgiye sahip olmadıklarını ifade etmiştir. Etkili bir elektronik geri kazanımı için, tüketiciler geri kazanım programları konusunda kesinlikle bilgilendirilmelidir. Kullanmış oldukları elektronik cihazlar kullanılamaz hale geldiğinde ya da teknolojik yenilikten ötürü işlevini yitirdiğinde bu tür cihazlarını nereye götürmeleri gerektiği konusunda tüketicilerin bilgilendirilmesi gerekir. Toplama zamanı, yeri ve bu merkezlere kabul edilebilecek atıklar konusunda yapılan bilgilendirmeleri içeren tanıtımlar, gazete, dergi, radyo, yerel televizyon kanalları ve el ilanları ile bölge halkına duyurulmalıdır. Seçilen reklam türü, tamamen bölge karakteristiklerine göre seçilmelidir. Kırsal ya da kentsel alan, yerleşim bölgesi ve/ya da ticari alanlarda bölgeye özgü farklı metotlar uygulanmalıdır. Örneğin ticari alan için gazete reklamı tercih edilebilirken, kırsal bölge için radyo ya da yerel TV reklamları tercih edilmelidir. Üniversite ya da büyük şirketlerde ise e-mail ile bilgilendirme etkili bir reklam metodu olarak tercih edilebilir (Kang \& Schoenung, 2005).

Soru 8. Sizce seçeneklerden (Batarya, televizyon, aydınlatma ürünleri (ampul, floresan, vb.), dizüstü bilgisayar, pil) hangisi/hangileri elektrikli ve elektronik atıklar içinde değerlendirilebilir? 
Katılanların çoğu birden fazla seçenek işaretlediği için 100 kişi ile yapılan anket çalışmasından Şekil 3'de verilen sonuç çıkmıştır. Pil ve batarya “AEEE'lerin Kontrolü Yönetmeliği'ne” göre değil “Tehlikeli Atıkların Kontrolü Yönetmeliği'ne" göre değerlendirilmektedir ve AEEE içinde bulunan tehlikeli bileşenlerdir. Ancak verilen cevaplardan katılımcıların elektrikli ve elektronik atık grupları hakkında yeterli bilgiye sahip olmadıkları anlaşılmaktadır.

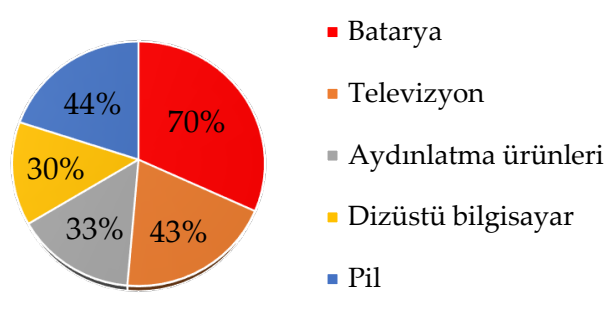

Şekil 3. Katılımcıların elektronik atık olarak sınıflandırdığı ürünler

Soru 9. Aşă̆ıdakilerden hangisi/hangileri (altın, cam, bakır, platin, arsenik, plastik) elektrikli ve elektronik ürünlerin içeriğinde bulunur? (Gerekli görüyorsanız birden fazla kutucuğu işaretleyebilirsiniz.)

Katılanların çoğu birden fazla seçenek işaretlediği için 100 kişi ile yapılan anket çalışmasında Şekil 4' den de görüldüğü üzere cevapların \%31'i altın, \%29'u cam, \%59'u bakır, \%22'si platin, \%13'ü arsenik, \%31'i plastik olmuştur.

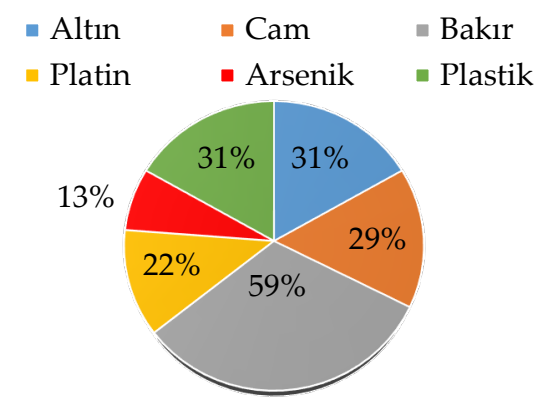

Şekil 4. Katılımcıların elektronik atık içeriği hakkındaki görüşleri 
Elektrikli ve elektronik ekipman atıkları bakır, alüminyum, kurşun, demir gibi metaller ve plastik gibi farklı materyallerin karışımından oluşur (Kang \& Schoenung, 2005). Verilen cevaplar katilımcların bu konuda doğru tahmin yaptıklarını göstermektedir. 7. soruda da katılımcların \%46'sı elektronik atıklarını hurdacıya verdiğini beyan etmiştir. Elektronik atıklar içindeki ana materyaller metal, plastik ve cam olduğu için verilen cevaplar da bu yöndedir, hurdacılar bu atıkları talep etmektedir. Ancak uygun olmayan kötü şartlarda ayrıştırma işlemi yapıldığı için hem çevre ve insan sağlığı olumsuz etkilenmekte, hem de elektronik atık içerisindeki diğer değerli metaller ayrıştırılmadığından ekonomik kayıp oluşmaktadır.

\section{Soru 10. Cep telefonunuzu ne sıklıkla değiştiriyorsunuz?}

Şekil 5'de görüldüğü üzere katılımcıların \%8'i 6-12 ay, \%42'si 2-4 yıl, $\% 50$ 'si ise 4-7 yıl arasında bir süreçte cep telefonunu değiştirdiğini söylemiştir. Katılımcıların \% 66'sının 20-40 yaş arasında olduğu düşünülürse, çıkan sonuç teknoloji bağımlılı̆̆ı ile ilişkilendirilebilir.

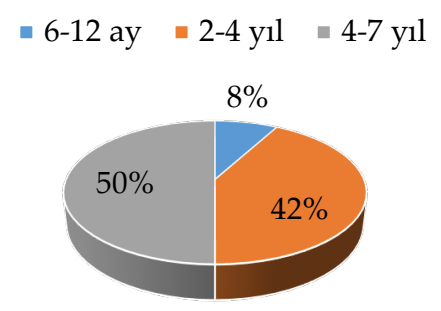

Şekil 5. Katılımcılarnn cep telefonu değiştirme sıklı̆̆ı

\section{Soru 11. Evinizdeki beyaz eşyalarınız hangi sıklıla yeniliyorsunuz?}

Teknolojideki gelişme ve hayatımıza getirdiği kolaylıklar nedeniyle elektrikli ve elektronik cihazlar günlük hayatımızın vazgeçilmez bir parçası haline gelmiştir. Tüketim alışkanlıkları gelişen teknoloji ile beraber hızla değişmekte, yeni modeller piyasaya sürülmekte, buna bağlı 
olarak da elektronik atıklar her geçen gün daha da artmaktadır. Bu bilgilerden yola çıkarak katılımcılara yöneltilen soruya verilen cevaplar Şekil 6'da verilmiştir.

$$
\text { - 3-5 y1 } \because 5-10 \mathrm{y} 1 \mathrm{l} \quad=10-15 \mathrm{y} 1 \mathrm{l}
$$

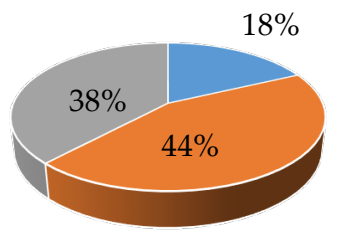

Şekil 6. Katılımcıların beyaz eşyaların değiştirme sıklı̆̆ı

Katılımciların \%77'sinin aylık geliri 1000-4000 TL arasında değişmesine rağmen \%18'i 3-5 yıl, \%44'ü 5-10 yıl, \%38'i 10-15 yılda bir beyaz eşyalarını değiştirdiğini ifade etmiştir. Beyaz eşya değiştirme sebepleri, çoğunlukla eşyaların bozulması ya da tamir edilemez duruma gelmesi ve teknolojiyi takip etme isteğidir. Bu sonuç gelir düzeyine bakılmaksızın her evden AEEE çıktığını göstermektedir.

Soru 12. Elektrikli ve elektronik ürünler arasında sıklıkla hangisini kullanıyorsunuz? (Gerekli görüyorsanız birden fazla kutucuğu işaretleyebilirsiniz.

Katılımcılar \%14 televizyon, \%34 bilgisayar, \%42 cep telefonu ve \%10 diğer cevabını vermiştir (Şekil 7). Katılımcıların çoğunluğunun cep telefonu ve bilgisayar cevabını verdiği görülmektedir. 


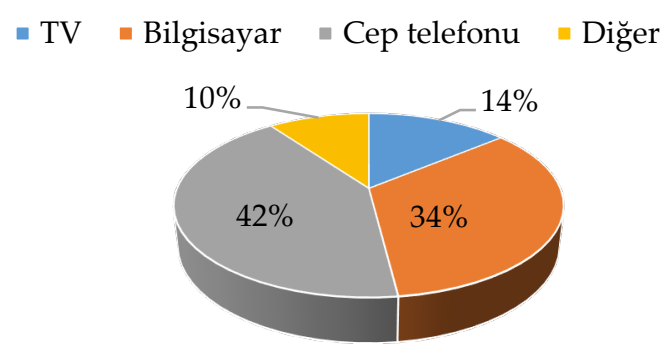

Şekil 7. Elektrikli ve elektronik ürünlerin kullanım oranı

Elektronik atıklarda yüksek miktarlarda bulunan zararlı maddelerin ayrılması geri dönüşüm sistemleri için önemli bir basamaktır. Bu zararlı bileşenler özellikle bilgisayar, televizyon, monitör, video, cd, radyo gibi aletlerde bulunan; ağır metaller (cıva, baryum, kadmiyum, kurşun, kalay), poliklorlu bifeniller, yanmaya dayanıklı malzemeler, kloroflorokarbonlar şeklinde sıralanabilir (Kamanlı, 2013).

Özellikle bilgisayar sektöründe yaşanan hızlı teknolojik gelişmeler nedeniyle ürünler ekonomik ömrünü tamamlamadan çöpe atılmaktadır. Dünya üzerinde her yıl çöpe atılan elektronik ürün miktarı 6 milyon ton civarındadır. Oysaki bu aşırı tüketim alışkanlığı tersine çevrilebilse hem çevrenin kirlenmesine engel olunacak hem de dünyanın fakir bölgelerinde bilgisayar imkanına sahip olmayan kişilere bu bilgisayarlar gönderilerek önemli bir toplumsal katkı sağlanacaktır. Birleşmiş Milletler tarafından yaptırılan bir araştırmaya göre bir bilgisayarın üretimi için ağırlı̆̆ kadar kimyasal madde (birçoğu zehirli), ağırlığının 10 katı kadar fosil kökenli yakıt ve 1,5 ton kadar da su kullanılmaktadır. Bu yüzden, dünya üzerinde geri dönüşüm ve geri kazanımı giderek daha fazla arzu edilir hale getirecek çalışmalara hız verilmelidir (https://www.bimel.com.tr/tr/rohs-ve-weee).

\section{Sonuç}

İçeriklerinde bulunan tehlikeli bileşenlerden dolayı uygun yönetilmediklerinde e-atıklar, çevre ve insan sağlığına zarar verir. Yeni yasal zorunluluklar, belediyelerin yönetmeliğe uygun hareket etmesi, toplumun e-atık konusunda eğitilmesi ve devletin lisanslı geri dönüşüm 
firmalarını desteklemesi ile elektronik atıkların zararı en aza indirilerek içeriğindeki geri kazanılabilir bileşenler ekonomiye geri kazandırılabilecektir. Bu nedenle evde tutulan EEE'lerin uygun bir şekilde tekrar kullanımını veya geri kazanımını sağlayacak stratejilerin ve politikaların oluşturulması gerekmektedir. Bu kapsamda e-atıkların ve bu atıkları oluşturan geri dönüşüme uygun tüm parçaların bu sürece dahil edilmesi ile çevre ve insan sağlığının korunmasının yanısıra değerli madde ve enerji tasarrufu da sağlanmış olacaktır.

Yapılan araştırma sonucunda katılımcıların, e-atık tehlikesinin farkında olmadığı anlaşılmaktadır. Bu atıkları yönetmek için ne yapmaları gerektiği konusunda da yeterli bilgiye sahip değillerdir. Belediye tarafından yeterli bilgilendirme ve yönlendirme yapılmazsa, e-atıklarını doğru bir şekilde elden çıarmak tüketiciler için çok zordur. Son kullanıcı konumundaki tüketicilerin e-atıkların geri dönüşüm sürecinin önemi hakkında bilgilendirilmesi, İldeki mevcut e-atık potansiyelinin değerlendirilmesine önemli bir katkı sağlayacaktır. Konu ile ilgili olarak AEEE'ler için İl bazında bir atık yönetim stratejisi oluşturulmalıdır. Belirli noktalara yerleştirilecek toplama kutuları ve toplama merkezlerine halkın e-atıklarını getirmeleri sağlanmalıdır. Zaten yapılan çalışmada katılımcıların \%74'ü atıklarını geri dönüşüm kutularına bırakabileceğini söylemiştir.

Bu çalışma Sivas İl merkezinde yaşayan bölge halkının e-atık tüketim alışkanlıkları, e-atık konusundaki bilgi düzeyi, e-atıklardan kurtulma konusundaki tutumu ve AEEE'lerin toplanması hususunda İl genelindeki durum hakkında önemli bilgiler vermektedir. Belediyeler, kanun ve yönetmeliklere uygun atık toplama ve bertaraf etme sorumluluklarının yanında topluma farkındalık kazandırmak için eğitim, konferans gibi faaliyetler de yürütmelidir. E-atıkları parçalayıp çevreye zararlı şekilde bırakan hurdacılara karşı da daha kapsamlı yasa ve yönetmelikler çıkarılabilir. Anket sonuçları ilgili merciler tarafından irdelenerek e-atık toplama konusunda yapılacak planlamalarda mutlaka kullanılmalıdır. Benzer bir araştırma e-atık yönetim stratejisi oluşturmak isteyen tüm belediyelerce de uygulanabilir. 


\title{
EXTENDED ABSTRACT
}

\section{Measurement of Awareness Level of Public in the Recycling of Electrical and Electronic Wastes: A Case of Sivas City}

\author{
İlknur Şentürk \\ Sivas Cumhuriyet University
}

As an inevitable consequence of technological progress in recent years, the increase in the consumption of electrical and electronic equipment in the world has brought with the problem of waste electrical and electronic equipment (WEEE). The problem of WEEE is much bigger than we thought, because of these wastes contain toxic substances and, occupy large areas. Today, recovering and recycling heavy metals in e-wastes under healthy conditions is very important for the environment and human health. At this point, both producers and consumers need to be more sensitive and informed about the issue. Since electrical and electronic devices contain many harmful components, e-wastes from these devices have different qualities than both municipal and industrial wastes, both chemically and physically. Due to these features, the devices must be properly recovered or disposed of when they have completed their useful life. Uncontrolled disposal of electrical and electronic wastes leads to the spread of infectious diseases and the enter of toxic substances into the food chain and the deterioration of the quality of drinking water. Since most of the chemicals in electronic devices are environmentally resistant, it is inevitable that they will have a negative impact on the environment and human health by staying in nature for many years.

The number and size of e-waste generated in Sivas are not fully known. In addition, no research has been conducted to analyze consumer behavior in disposing of electrical electronic wastes. Since consumer behavior towards e-waste disposal is highly effective in increasing environmental risks, research is needed like this. The aim of the study was to determine the attitudes, behavior, knowledge level and habits of the people living in the province of Sivas on the recovery of electrical and 
electronic wastes. The results of the research will be guiding in the implementation of the activities carried out for the recovery and collection of WEEEs in a more efficient way, in the elimination of the problems encountered in the implementation, in the planning of policies, and training for the recovery of such wastes.

A questionnaire composed of 12 different questions was conducted by interviewing 100 people with different occupation levels, age, and occupation. $23 \%$ of the surveyed individuals were interviewed on the street, $42 \%$ at home, $35 \%$ at the workplace. It is understood from the research results that the participants are not aware of the danger of ewastes. They do not have enough information about what they should do to manage these wastes. If the municipality does not provide adequate information and guidance, it is very difficult for consumers to dispose of their e-wastes correctly. Informing end-users about the importance of ewaste recycling process will make a significant difference in the evaluation of the current e-waste potential in the province. A waste management strategy should be established for WEEEs. The collection boxes and collection centers to be placed at certain points should be provided to bring the people's e-wastes. In this study, $74 \%$ of the participants stated that they could leave their wastes to the recycling bins.

This study provides important information about e-waste consumption habits of the people living in the city center of Sivas, the level of knowledge, the attitudes for recovery and the situation in the province for the collection of WEEE. The results of the survey should be examined by the relevant authorities, and e used in the planning of e-waste collection.

\section{Kaynakça / References}

Akın, B. ve Kuru, A. (2011). Elektrikli ve elektronik atıkların zararları, yönetimi ve Türkiye'deki uygulamalarının değerlendirilmesi. İstanbul Aydın Üniversitesi Dergisi (İÄ̈D), 3(12), 1-12. 
Ay, E. (2012). Atık elektrikli ve elektronik eşyaların geri kazanımının değerlendirilmesi ve Samsun ilinde seçilen pilot bir bölgede uygulanması. Yüksek lisans tezi. Ondokuz Mayıs Üniversitesi Fen Bilimleri Enstitüsü, Samsun.

Aydın, Ç. Y., ve Kiraz, E. D. E. (2017). Elektronik atıklar ve çevre sağlığı. Adnan Menderes Üniversitesi Sağllk Bilimleri Fakültesi Dergisi, 1 (1), 39-52.

Baldé, C.P., Wang, F., Kuehr, R., ve Huisman, J. (2014). The global E-waste Monitor - 2014, United Nations University, IAS - SCYCLE, Bonn, Germany.

Burke, M. (2007). The gadget scrap heap. Chemistry World, 4(6), 45-48.

Çelik, C. (2007). Elektrik elektronik atıklardan metal ve plastik geri kazanımının araştırılması. Yüksek lisans tezi. İstanbul Teknik Üniversitesi Fen Bilimleri Enstitüsü, İstanbul.

Çiftlik, S., Handırı, İ., Beyhan, M., Akçil, A., Ilgar, M., ve Gönüllü, M. T. (2011). Evaluation of management, economy and the potential of metal recovery of electrical and electronic wastes (E-waste). Journal of Engineering and Natural Sciences, Sigma, 3, 261-267.

Gündüzalp, A. A., ve Güven, S., (2016). Atık, çeşitleri, atık yönetimi, geri dönüşüm ve tüketici: Çankaya belediyesi ve semt tüketicileri örneği. Hacettepe Üniversitesi Sosyolojik Araştırmalar E-Dergisi, 1-19.

He, W., Li, G., Ma, X., Wang, H., Huang, J., Xu, M., Huang, C. (2006). WEEE recovery strategies and the WEEE treatment status in China. Journal of Hazardous Materials, B136, 502-512. https://doi.org/10.1016/j.jhazmat.2006.04.060.

https://www.bimel.com.tr/tr/rohs-ve-weee, Erişim tarihi: 23.01.2019.

Huang C. L., Bao L. J., Luo, P., Wang, Z. Y., Li, S. M., ve Zeng, E. Y. (2016). Potential Health Risk for Residents Around a Typical E-Waste Recycling Zone Via Inhalation of Size-Fractionated Particle-Bound Heavy Metals. Journal of Hazardous Materials 5 (317), 449-456.

İnce, M.Y. (2011, 14 Mart). Çevresel değerler, elektronik atık sorunu, uygulamalar ve çözüm önerilerine genel bir bakış. http://www.eatik.com/, Erişim tarihi: 15.06.2018. 
Kamanlı, A. (2013). Ankara büyükşehir belediyesi stnırları içinde oluşan ambalaj atıklarn ile elektrikli ve elektronik atıklarm belirlenmesi ve ekonomik analizi. Yüksek lisans tezi. Gazi Üniversitesi Fen Bilimleri Enstitüsü, Ankara.

Kang, H. Y. ve Schoenung, J. M. (2005). Electronic waste recycling: A review of U.S. infrastructure and technology options. Resources, Conservation and Recycling, 45, 368-400. https://doi.org/10.1016/j.resconrec.2005.06.001.

Karagözoğlu, M. B., Özyonar, F., Yılmaz, A.,ve Atmaca, E. (2009). Katık atıkların yeniden kazanımı ve önemi. TÜRKAY 2009 Türkiye'de Katı Atık Yönetimi Sempozyumu, YTÜ, 15-17 Haziran 2009.

Kaya, Ü., Koruca, H. İ., 2018. Elektronik atıkların çevreye etkisi ve topluma farkındalık kazandırmak için öneriler. Akademik Sosyal Araştırmalar Dergisi 6(73), 368-378.

Mburu, P. T. \& Tuduetso, T. (2013). Investigation of consumer behavior on discarding of their electrical/electronic waste: A case of Gaborone city. E3 Journal of Business Management and Economics, 4(9), 200-205.

Neira, J., Favret, L., Fuji, M., Miller, R., Mahdavi, S., ve Blass, V. D. (2006). End-of-life management of cell phones in the United States. Editör: Roland Geyer, University of California, Santa Barbara. https://doi.org/10.1109/ISEE.2008.4562849

Özkan, A. (2018). Atık baskılı devre kartlarından değerli metal geri kazanım yöntemlerinin çok ölçütlü karar verme teknikleri ile değerlendirilmesi. AKÜ FEMÜBİD, 18, 529-537.

Resmi Gazete, Sayı 28300, 22 Mayı 2012. http://www.resmigazete.gov.tr/eskiler/2012/05/20120522-5.htm.

Robinson, B. H. (2009). E-waste: An assessment of global production and environmental impacts. Science of the Total Environment, 408, 183191. https://doi.org/10.1016/j.scitotenv.2009.09.044.

Salihoğlu, G., Kahraman, A. E. (2016). Türkiye'de elektrikli ve elektronik atık üretimi: Bursa örneği. Uludă̆ Üniversitesi Mühendislik Fakültesi Dergisi, 21 (2), 95-106. 
Sjodin, A., Patterson Jr., D. G., Bergman, A. (2003). A review on human exposure to brominated flame retardants-particularly polybrominated diphenyl ethers. Environment International, 29, 829-839. https://doi.org/10.1016/S0160-4120(03)00108-9.

U.S. Environmental Protection Agency (2001). Electronics new opportunity for waste prevention, Reuse, and Recycling.

Yazıcı, E. Y. ve Deveci, H. (2009). E-atıklardan metallerin geri kazanımı. Madencilik, 48 (3), 3-18.

\section{Kaynakça Bilgisi / Citation Information}

Şentürk, İ. (2019). Elektrikli ve elektronik eşya atıklarının geri dönüşümü konusunda halkın bilinç düzeyinin ölçülmesi: Sivas ili örneği. OPUS-Uluslararası Toplum Araştırmaları Dergisi, 11(18), 956-978. DOI: 10.26466/opus.548371 